OPEN ACCESS

Edited by:

Guanghui Zhang

Dalian University of Technology, China

Reviewed by:

Zhenghong Bao,

Oak Ridge National Laboratory,

United States

Zhuoran Xu,

BP North America Inc, United States

*Correspondence:

Maria Olea

m.olea@tees.ac.uk

Specialty section: This article was submitted to

Catalytic Engineering,

a section of the journal

Frontiers in Chemical Engineering

Received: 25 January 2020

Accepted: 30 July 2020

Published: 08 October 2020

Citation:

Ahmed R, Sasaki T and Olea M (2020) Original Method to Predict and Monitor Carbon Deposition on Ni-Based Catalysts During Dry Reforming of Methane. Front. Chem. Eng. 2:9.

doi: $10.3389 /$ fceng.2020.00009

\section{Original Method to Predict and Monitor Carbon Deposition on Ni-Based Catalysts During Dry Reforming of Methane}

\author{
Rawaz Ahmed ${ }^{1}$, Takehiko Sasaki ${ }^{2}$ and Maria Olea ${ }^{\text {1* }}$ \\ ${ }^{1}$ School of Science, Engineering and Design, Teesside University, Middlesbrough, United Kingdom, ${ }^{2}$ Graduate School of \\ Frontier Sciences, The University of Tokyo, Tokyo, Japan
}

Although catalytic dry reforming of methane has recently attracted considerable attention from both environmental and economical points of view, due to the simultaneous utilization of two greenhouses with a high environmental impact, $\mathrm{CO}_{2}$ and $\mathrm{CH}_{4}$, and to the production of syngas ( $\mathrm{CO}$ and $\mathrm{H}_{2}$ mixtures), a building block used for the synthesis of valuable chemicals and synthetic fuels, it has not yet been commercialized. Low-cost $\mathrm{Ni}$-based catalysts with high activity have been developed. However, due to their major drawbacks (such as carbon formation and Ni particles sintering at high temperatures, which is required by the endothermic reaction), their industrial applicability is limited. What is more, access to advanced characterization techniques is needed to monitor coke deposition and to assess the efficiency of the dry reforming process, access which can be challenging for small and on-site laboratories. The focus of this current study is on the development and testing of a simple carbon deposition prediction method, which is easily accessible, based on the comparison of the gas composition measured at the exit of the reactor with the theoretical one, and calculated based on the process thermodynamics. Trustworthy results, confirmed by SEM and TGA/DSC measurements, were obtained when the method was applied for the monometallic, Ni/SBA-15, prepared by wet impregnation, and bimetallic, Ni-Co/SBA-15, and Ni-La/SBA-15 samples, prepared by both impregnation and co-impregnation, with different metal loading. The dry reforming process was performed at four temperatures: $550,600,650$, and $700^{\circ} \mathrm{C}$.

\footnotetext{
Keywords: dry reforming of methane, Ni-based catalysts, precursors, nickel acetate, nickel nitrate, carbon deposition prediction, original method
}

\section{INTRODUCTION}

The transformation of biomass into valuable chemicals and fuels, using advanced processing methods and cutting-edge technologies, is becoming increasingly popular and challenging. Seen as a way to mitigate global warming and to diversify energy sources, the use of biomass for fuels, power production, and products that would otherwise be made from fossil fuels provides many benefits. The anaerobic digestion of biodegradable materials, such as livestock manure, food waste, municipal wastewater solids, fats, oils, and grease, to produce mainly biogas, $24 \mathrm{~h}$ a day, 7 days a week, is one of those advanced technologies. Refined processing of biogas via catalytic dry (or $\mathrm{CO}_{2}$ ) reforming of methane (DRM) qualifies as a valuable route to produce syngas with a $\mathrm{H}_{2} / \mathrm{CO}$ 
ratio highly suited for the downstream conversion of biomass into long-chain hydrocarbons via the Fischer-Tropsch reaction.

The DRM process for syngas production involves a series of complex chemical reactions. The reactants ratio, the operational pressure, and temperature are important factors in generating a high yield of syngas without considerable side reactions that lead to undesired by-products. Besides the main reaction illustrated by Equation 1, there are several other series/parallel side reactions, which involve reactions between the reactants and the products of the DRM reaction. These side reactions include RWGS (Reverse Water Gas Shift) reaction (Equation 2), methane decomposition (Equation 3), CO disproportionation reaction or Boudouard reaction (Equation 4), and reverse carbon gasification reaction (Equation 5), as shown below (Tsai and Wang, 2008; Al-Fatish et al., 2009).

$$
\begin{aligned}
& \mathrm{CH}_{4}+\mathrm{CO}_{2} \leftrightarrow 2 \mathrm{H}_{2}+2 \mathrm{CO} \Delta \mathrm{H}_{298}^{o} \\
& =247 \mathrm{~kJ} / \mathrm{mol}(\text { Dry reforming }) \\
& \mathrm{H}_{2}+\mathrm{CO}_{2} \leftrightarrow \mathrm{H}_{2} \mathrm{O}+\mathrm{CO} \Delta \mathrm{H}_{298}^{o} \\
& =41 \mathrm{~kJ} / \mathrm{mol}(\text { Reverse water gas shift }) \\
& \mathrm{CH}_{4} \leftrightarrow \mathrm{C}+2 \mathrm{H}_{2} \quad \Delta \mathrm{H}_{298}^{o} \\
& =75 \mathrm{~kJ} / \mathrm{mol}(\text { Methane dissociation }) \\
& 2 \mathrm{CO} \leftrightarrow \mathrm{CO}_{2}+\mathrm{C} \quad \Delta \mathrm{H}_{298}^{o} \\
& =-171 \mathrm{~kJ} / \operatorname{mol}(\mathrm{CO} \text { disproportionation }) \\
& \mathrm{CO}+\mathrm{H}_{2} \leftrightarrow \mathrm{C}+\mathrm{H}_{2} \mathrm{O} \quad \Delta \mathrm{H}_{298}^{o} \\
& =-131 \mathrm{~kJ} / \mathrm{mol}(\text { Reverse carbon gasification })
\end{aligned}
$$

For the strongly endothermic reaction of dry reforming, the equilibrium conversion increases significantly with increasing reaction temperature. The equilibrium conversion of the moderate endothermic reactions, methane decomposition, and the reverse water-gas shift reaction also increase with temperature. The two carbon deposition reactions, the disproportionation reaction, and the reverse carbon gasification reaction are exothermic and thermodynamically unfavorable at high temperatures. Reaction temperatures above $750^{\circ} \mathrm{C}$ are required to reach a high equilibrium conversion value of $\mathrm{CH}_{4}$ and $\mathrm{CO}_{2}$ and to minimize the carbon formation through methane cracking and Boudouard reactions (Edwards and Maitra, 1995).

Group VIII B metals, like Co, Ni, Pt, Ru, Rh, and Ir, supported on alumina, titania, silica, or zirconia, were reported to show high catalytic activity in DRM reactions (Verykios, 2003); conversions approaching those defined by thermodynamics can be achieved as long as reaction temperature and contact time are sufficiently high.

However, as seen above, the major drawback of the DRM reaction is the coke formation which may cause catalysts' deactivation and clogging of the reactor. Although the noble metal-based catalysts provide lower carbon deposition in a DRM reaction than the Ni-based catalysts, their scarcity and high cost restrict their practicability. Therefore, recent studies on dry reforming of methane were focused on the development of $\mathrm{Ni}$ based catalysts with high coking resistance and thermal stability
(Arbag et al., 2016; Akri et al., 2019 and References herewith). Various methods, including the effect of supports Bradford and Vannice, 1999, the loading of metal San José-Alonso et al., 2013, the preparation method Xu et al., 2001, the use of promoters (Zhu et al., 2011) and the doping of other metals (Nikolla et al., 2007; Liu et al., 2009a,b), have therefore been investigated to improve the catalytic performance of $\mathrm{Ni}$-based catalysts. It has been shown that the coke formation resistance of the Ni-based catalysts can be increased by adding alkali, alkaline, or lanthanide oxides or small amounts of noble metals, or by using the synergetic effect between $\mathrm{Ni}$ and Co. What is more, the preparation procedure for the bimetallic catalysts, such as co-impregnation or sequential impregnation, has significant effects on the resistance of carbon formation during the reaction (Erdogan et al., 2018).

Another significant factor influencing the catalytic performance and coke formation is the surface acidity of the supporting materials: the higher the surface acidity, the higher the amount of coke formed during dry reforming (Benrabaa et al., 2015). After the discovery of mesoporous silica (i.e., SBA-15, MCM-41) materials with ordered pore structures, studies on the synthesis of the mesoporous materials as catalyst support increased due to the elimination of the mass transfer limitation of reactants and/or products (Lin et al., 2002; Hukkamäki et al., 2004), andto the prevention of coke formation by their relative low surface acidity. (Huang et al., 2015), reported a superior performance of the SBA-15 supported bimetallic Ni-Co catalysts compared with that of monometallic catalysts in the dry reforming of methane.

To the best of our knowledge, there are no commercial DRM processes to date because of catalyst deactivation by coking and sintering of Ni species, although, as discussed above, considerable research effort has been put toward the developing of catalysts able to overcome these drawbacks. What is more, a thorough physical and chemical characterization of possible candidates, using advanced techniques, is required in order to select the best catalysts and to monitor their behavior during the DRM process. However, access to these techniques is rather challenging for small or on-site laboratories. Therefore, a simple method that does not require sophisticated techniques to monitor the carbon deposition over Ni-based catalysts during the dry reforming of methane process, at lab, pilot and, more importantly, at a commercial scale as well, when the commercialization will be fully operational, is of great demand.

Considering all these observations, the present study proposes an original method to predict the carbon deposition over monometallic and bimetallic Ni-based catalysts, supported on mesoporous silica, SBA-15, and attempts to contribute to the understanding of the carbon deposition process during the dry reforming of methane over these catalysts. The proposed prediction method has been successfully tested in the case of monometallic Ni/SBA-15 and bimetallic Ni-Co/SBA-15 and NiLa/SBA-15 catalysts with increased metal loadings.

The authors would like to reiterate that the main aim of this paper was to share the original method which can be used to predict coke formation over different $\mathrm{Ni}$-based catalysts, saving time and resources when testing a series of Ni-based catalysts in order to choose the one which, along with having rather 
high activity, will not favor the coke deposition for the DRM process and not to systematically study the DRM reaction on the monometallic and bimetallic Ni-based catalysts.

Therefore, the results most significant and pertinent to this study, obtained by Ahmed (2013) (who performed a systematical study on Ni-based catalysts for DRM), with additional contribution on data analysis from the co-authors, were gathered and presented within this study, to support and to confirm the correctness of the proposed method.

\section{MATERIALS AND METHODS}

\section{Preparation of SBA-15}

The general experimental procedure followed in the preparation of mesoporous silica, via sol-gel method, was described in detail by Zhao et al. (1998a,b). This procedure was modified and the preparation conditions, such are the amount of $P_{123}$, type of acid, and aging time, were optimized through experiments (Ahmed, 2013). The optimized procedure is described below.

Therefore, $8 \mathrm{~g}$ of tri-block co-polymer of Poly (Ethylene oxide)-Poly (Propylene oxide)-Poly (Ethylene oxide) $\left(\mathrm{EO}_{20} \mathrm{PO}_{70} \mathrm{EO}_{20}\right.$, Pluronic P123) (Sigma-Aldrich) were added to $240 \mathrm{~g}$ of de-ionized (DI) water and kept at $40^{\circ} \mathrm{C}$ under stirring at $\sim 540 \mathrm{rpm}$ for $6 \mathrm{~h}$, until a clear solution was observed as a result of the complete mixing of P123 in water.

Then, $40 \mathrm{ml}$ of $\mathrm{HCl}$ (37 wt\%) (Fisher Scientific) was added to the dissolved P123 in water to reduce the $\mathrm{pH}$ of the solution and, $\sim 10 \mathrm{~min}$ later, $18.5 \mathrm{ml}$ of Tetra Ethyl Ortho-Silicate (TEOS) (Sigma-Aldrich) was added dropwise in $25-30 \mathrm{drop} / \mathrm{min}$ to the solution under vigorous stirring. The solution was then kept under stirring at $\sim 540 \mathrm{rpm}$ for hydrolysis and condensation reactions for $20 \mathrm{~h}$. A white precipitate was formed which was transferred to an oil bath and kept at $95^{\circ} \mathrm{C}$ for $24 \mathrm{~h}$ to age without stirring. The white precipitate was then filtered, washed with $\sim 600 \mathrm{ml}$ of DI water to remove the template (P123), and afterwards dried at $60^{\circ} \mathrm{C}$ for $24 \mathrm{~h}$. The white powder was then calcined at $550^{\circ} \mathrm{C}$ under steady state conditions for $6 \mathrm{~h}$. The heating rate was $10^{\circ} \mathrm{C} / \mathrm{min}$. Afterwards, $100 \mathrm{~g}$ of DI water was added to the calcined white powder in a round bottom flask and a short condenser inserted into the round bottom flask. The solution was then placed on a hot plate and left to boil for $2 \mathrm{~h}$ at $105^{\circ} \mathrm{C}$ with gentle stirring for surface hydration. After $2 \mathrm{~h}$, the mixed solution was then filtered and a pure $4 \mathrm{~g}$ of SBA-15 sample was collected and dried at $120^{\circ} \mathrm{C}$ for $6 \mathrm{~h}$.

\section{Preparation of Monometallic Ni/SBA-15 Samples}

The wet impregnation method was chosen for the preparation of the monometallic Ni-based samples. As precursors, nickel (II) acetate tetra-hydrate $\left[\mathrm{Ni}\left(\mathrm{CH}_{3} \mathrm{COO}\right)_{2} \cdot 4 \mathrm{H}_{2} \mathrm{O}(99 \%)\right.$, average molecular weight 248.86] and nickel (II) nitrate hexa-hydrate $\left[\mathrm{Ni}\left(\mathrm{NO}_{3}\right)_{2} \cdot 6 \mathrm{H}_{2} \mathrm{O}\right.$ (99\%) (Sigma-Aldrich) were used. DI water was used throughout the experiments.

The impregnation was carried out at different temperatures, for different impregnation times and different impregnation treatments. Samples were prepared and labeled, as shown in Table 1.

The impregnation temperature was higher for nickel acetate than for nickel nitrate because of its lower solubility in water. For example, at $20^{\circ} \mathrm{C}$, the solubility of nickel nitrate is $94 \mathrm{~g} / 100 \mathrm{ml}$ in water, while for nickel acetate the solubility is only $17 \mathrm{~g} / 100 \mathrm{ml}$. The calcinations temperature was chosen as $550^{\circ} \mathrm{C}$, because at too low a temperature (e.g., $200^{\circ} \mathrm{C}$ ), the nickel salt does not have a complete decomposition to form $\mathrm{NiO}$, whereas at too high a calcination temperature (e.g., $800^{\circ} \mathrm{C}$ ), the sintering and /or fusing of nickel active sites through the annealing effects can occur (Steinhauer et al., 2009). Therefore, all samples were calcined in air atmosphere at $550^{\circ} \mathrm{C}$, for $2 \mathrm{~h}$, at a heating rate of $10^{\circ} \mathrm{C} / \mathrm{min}$.

\section{Preparation of Bimetallic Ni-Metal/SBA-15 Samples ( $\mathrm{Me}=\mathrm{Co}$ and $\mathrm{La}$ )}

For the preparation of the bimetallic samples, both the sequential and co-impregnation methods were employed, using lanthanum (III) nitrate hexa-hydrate $\left[\mathrm{La}\left(\mathrm{NO}_{3}\right)_{3} \quad 6 \mathrm{H}_{2} \mathrm{O},(99.99 \%)\right.$, average molecular weight 433.01], cobalt (II) nitrate hexa-hydrate [Co $\left(\mathrm{NO}_{3}\right)_{2} \quad 6 \mathrm{H}_{2} \mathrm{O}(98 \%)$, average molecular weight 291.03], and cobalt (II) acetate tetra-hydrate [Co $\left(\mathrm{CH}_{3} \mathrm{COO}\right)_{2 .} 4 \mathrm{H}_{2} \mathrm{O}$ (98.00\%), average molecular weight 249.08] as precursors. The following samples were prepared and labeled as shown in Table 2.

TABLE 1 | Preparation conditions and labels for the monometallic Ni/SBA-15 samples.

\begin{tabular}{|c|c|c|c|c|c|}
\hline \multirow[t]{2}{*}{ Precursor } & \multirow{2}{*}{$\begin{array}{c}\text { SBA-15:Ni-salt: DI } \\
\text { water (wt ratio) }\end{array}$} & \multirow[t]{2}{*}{ IMP. Time (h) } & \multicolumn{2}{|c|}{ Heat treatment } & \multirow[t]{2}{*}{ Label$^{*}$ XIMPNi } \\
\hline & & & $\begin{array}{l}\text { IMP. Temp } \\
\left({ }^{\circ} \mathrm{C}\right)\end{array}$ & Drying & \\
\hline \multirow[t]{2}{*}{$\mathrm{Ni}$-acetate } & $3: 1: 10$ & 10 & $90-95$ & dried at $120^{\circ} \mathrm{C}, 10 \mathrm{~h}$ & 4IMPNiA-A \\
\hline & $3: 2: 10$ & & & & 9IMPNiA-B \\
\hline \multirow{2}{*}{ Ni-nitrate } & $3: 2: 10$ & & & & 12IMPNiN-B \\
\hline & $3: 3: 10$ & & & & 29IMPNiN-C \\
\hline
\end{tabular}

* $X$ is the wt\% of nickel loaded as NiO, determined from EDX, IMP refers to impregnation, NiA, Ni-acetate; NiN, Ni-nitrate. 
TABLE 2 | Preparation conditions and labels for the bimetallic Ni-Metal/SBA-15 samples.

\begin{tabular}{|c|c|c|c|c|c|c|c|c|}
\hline \multirow[t]{2}{*}{ Precursor } & \multirow{2}{*}{$\begin{array}{l}\text { IMP. Time }=1-2 \mathrm{~h} \text {, } \\
\text { Temp }=50-60^{\circ} \mathrm{C} \\
\text { SBA-15: Co or La : DI } \\
\text { water (wt ratio) }\end{array}$} & \multicolumn{2}{|c|}{ Heat-treatment } & \multirow[t]{2}{*}{ Precursor } & \multirow{2}{*}{$\begin{array}{l}\text { IMP. Time }=1-2 \mathrm{~h} \text {, } \\
\text { Temp }=50-60^{\circ} \mathrm{C} \\
\text { Samples: Ni: DI } \\
\text { water (wt ratio) }\end{array}$} & \multicolumn{2}{|c|}{ Heat-treatment } & \multirow[t]{2}{*}{ Label $^{\star \star}$} \\
\hline & & Drying* & Calc. & & & Drying* & Calc. & \\
\hline \multicolumn{9}{|c|}{ Sequential impregnation method } \\
\hline \multirow[t]{3}{*}{ Co-acetate } & $1: 0.33: 10$ & $100^{\circ} \mathrm{C}, 1 \mathrm{~h}$ & $\begin{array}{l}400^{\circ} \mathrm{C}, 5 \mathrm{~h}, \\
10^{\circ} / \mathrm{min}\end{array}$ & Ni-acetate & 0.78:0.78:10 & $100^{\circ} \mathrm{C}, 1 \mathrm{~h}$ & $\begin{array}{l}650^{\circ} \mathrm{C} 4 \mathrm{~h}, \\
10^{\circ} / \mathrm{min}\end{array}$ & 9 IMPNi2CoA-A \\
\hline & $1: 0.67: 10$ & & & & $0.85: 1.5: 10$ & & & 15IMPNi4CoA-B \\
\hline & $1: 1: 10$ & & & & $0.96: 2: 10$ & & & 16IMPNi8CoA-C \\
\hline \multirow[t]{3}{*}{ La-nitrate } & $2: 0.67: 20$ & $100^{\circ} \mathrm{C}, 1 \mathrm{~h}$ & $\begin{array}{l}550^{\circ} \mathrm{C}, 2 \mathrm{~h}, \\
5^{\circ} / \mathrm{min}\end{array}$ & Ni-nitrate & $1.77: 1.52: 18$ & $100^{\circ} \mathrm{C}, 1 \mathrm{~h}$ & $\begin{array}{l}550^{\circ} \mathrm{C} \\
2 \mathrm{~h}, 5^{\circ} / \mathrm{min}\end{array}$ & 10IMPNi6LaN-A \\
\hline & $2: 1.33: 20$ & & & & 1.9:2:18.9 & & & 13IMPNi18LaN-B \\
\hline & $2: 2: 20$ & & & & $1.87: 2.5: 18.7$ & & & 16IMPNi11LaN-C \\
\hline
\end{tabular}

Co-impregnation method

\begin{tabular}{|c|c|c|c|c|c|}
\hline \multirow[t]{2}{*}{ Precursor } & \multirow{2}{*}{$\begin{array}{c}\text { SBA-15: Co or La :Ni :DI } \\
\text { water (wt ratio) }\end{array}$} & \multirow[t]{2}{*}{ IMP. Time \& Temp } & \multicolumn{2}{|c|}{ Heat-treatment } & \multirow[t]{2}{*}{ Label** $^{\star *}$} \\
\hline & & & Drying* & Calc. & \\
\hline $\begin{array}{l}\text { Co-nitrate } \\
\text { Ni-nitrate }\end{array}$ & 1:1.33:1.33:10 & $1-2 \mathrm{~h}, 40-50^{\circ} \mathrm{C}$ & $100^{\circ} \mathrm{C}, 1 \mathrm{~h}$ & $\begin{array}{l}550^{\circ} \mathrm{C}, 5 \mathrm{~h} \\
5^{\circ} / \mathrm{min}\end{array}$ & 12COIMPNi11CoN-C \\
\hline $\begin{array}{l}\text { La-nitrate } \\
\text { Ni-nitrate }\end{array}$ & $1: 0.67: 0.67: 10$ & $1-2 \mathrm{~h}, 40-50^{\circ} \mathrm{C}$ & $100^{\circ} \mathrm{C}, 1 \mathrm{~h}$ & $\begin{array}{l}550^{\circ} \mathrm{C}, 5 \mathrm{~h} \\
5^{\circ} / \mathrm{min}\end{array}$ & 4COIMPNi12LaN-B \\
\hline
\end{tabular}

*vacuum oven; Calc, Calcination.

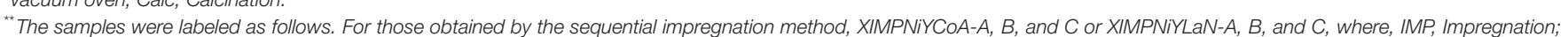

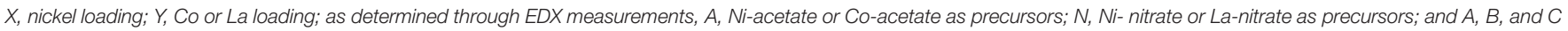
refers to the initial concentration of the precursor solution. As for those obtained by co-impregnation, the "IMP" in the label was replaced by "COIMP".

\section{Original Method to Predict the Carbon Deposition}

The method is based on the results obtained while measuring the catalytic activity of the monometallic and bimetallic Nibased samples toward the DRM reaction, by using a CATLAB system (Hiden Analytical, UK). The system comprises the Hiden Analytical QIC-20 dynamic sampling mass spectrometer (MS) and the CATLAB microreactor module with the units seamlessly integrated to provide one of the most versatile and accurate catalysts' characterization system available.

The below procedure to convert the voltage signal of the MS into partial pressure was followed.

The amplifier in the detector measures the ion flow on the Faraday cup. This is then converted using the $1 \times 10 \mathrm{e}-4 \mathrm{~A} /$ torr or $1 \times 10 \mathrm{e}-4 \mathrm{~A} / \mathrm{mbar}$, depending on which pressure units are used within the RC interface.

This is a calibration factor that has been pre-determined as the average sensitivity of Hiden Analytical products.

When an instrument is tested in production, it is tested to this spec to ensure it measures close to this performance.

At the beginning of the measurements, the fragmentation patterns for each of the gases were measured. Since fragments of different products can occur on the same AMU's, care should be taken when ascribing an AMU to a certain product. Therefore, the species of interest were admitted over a reactor filled with inert particles and catalyst particles, respectively. Comparison of both spectra gave an indication about which AMU's can be ascribed to reactants or products. Moreover, if different products appear on the same AMU, the fraction of each at that respective AMU could be determined and later subtracted for an accurate value of the partial pressure of the species of interest.

The fragmentation peaks can also be found online at NIST Mass Spectrometry Data Center (http://webbook.nist.gov/ chemistry/).

When $\mathrm{CO}_{2}$ was measured at AMU 44, as the other present species did not have a fragmentation peak at AMU 44, we considered its partial pressure as it was read.

When CO was measured at AMU 28, the contribution to the signal from the $\mathrm{CO}_{2}$ fragmentation pattern (which was about $10 \%$, similar to that from NIST) was subtracted from the response.

Thus, the $\mathrm{CO}_{2}$ reforming of the methane reaction was conducted under atmospheric pressure and constant temperature, namely $550,600,650$, and $700^{\circ} \mathrm{C}$, respectively, in the CATLAB system. About $25 \mathrm{mg}$ of each sample was firstly reduced under a 5 vol. $\% \mathrm{H}_{2}$ in Ar flow at $20 \mathrm{ml} / \mathrm{min}$ and 
then exposed to the reaction mixture of $100 \mathrm{ml} / \mathrm{min}$ flow, with $\mathrm{CH}_{4} / \mathrm{CO}_{2}=1.5: 1$, for $3 \mathrm{~h}$.

The choice of reaction time of $3 \mathrm{~h}$ was based on the following judgment. As mentioned in this study, there are no commercial DRM processes to date, due to catalyst deactivation by coking and to the sintering of $\mathrm{Ni}$ species. Both deactivation processes impact significantly into the lifetime of the catalysts. It is wellknown that the determination of catalytic activity, selectivity, and lifetime of industrial catalysts is an expensive and timeconsuming task. Therefore, accelerated testing procedures are foreseen. As such, preliminary testing of the sample, which was more prone to coke deposition, i.e., 29IMPNiN-C, for different time-on-stream, up to $50 \mathrm{~h}$, was performed. It was observed from TGA/DSC that the amount of carbon deposited stays constant after $3 \mathrm{~h}$.

The analysis of the effluent was carried out using the quadruple mass spectrometer, QIC-20. The following amus were measured: $2\left(\mathrm{H}_{2}\right), 40(\mathrm{Ar}), 18\left(\mathrm{H}_{2} \mathrm{O}\right), 15\left(\mathrm{CH}_{4}\right), 28(\mathrm{CO})$, $32\left(\mathrm{O}_{2}\right)$, and $44\left(\mathrm{CO}_{2}\right)$. As mentioned above, the integrated software allowed the conversion of intensity of the amu into the pressure and as such, in this work, the conversions, $X$, of the limiting reactant, $\mathrm{CO}_{2}$, was calculated according to the following equation:

$$
X_{\mathrm{CO}_{2}}=\frac{P_{\mathrm{CO}_{2}}^{o}-P_{\mathrm{CO}_{2}}}{P_{\mathrm{CO}_{2}}^{o}} * 100
$$

Moreover, assuming that only the reforming reaction occurred, the theoretical pressure of methane leaving the reactor was calculated according to the following equation and was compared with the measured methane pressure. Then, the difference, $\Delta$, between the two values was calculated.

Theoretically,

$$
P_{\mathrm{CH}_{4} \mathrm{~T}}=P_{\mathrm{CO}_{2}}^{o}\left(1.5-X_{\mathrm{CO}_{2}}\right) \text { and } \Delta=P_{\mathrm{CH}_{4} \mathrm{~T}}-P_{\mathrm{CH}_{4}}
$$

where, $P_{\mathrm{CO}_{2}}^{\mathrm{O}}$ is the initial pressure of $\mathrm{CO}_{2}$ and $\mathrm{X}_{\mathrm{CO} 2}$ is the $\mathrm{CO}_{2}$ fractional conversion, while $\mathrm{P}_{\mathrm{CH}_{4}}$ and $\mathrm{P}_{\mathrm{CO}_{2}}$ are the pressure of $\mathrm{CH}_{4}$ and $\mathrm{CO}_{2}$, respectively, leaving the reactor.

The coke is formed only if the side reactions 3, 4, and 5 occur, as shown above. However, from a thermodynamic point of view, only reaction 3 is probable at the reaction temperatures (reaction 3 is endothermic, while 4 and 5 are strongly exothermic) (See Supplementary materials for Thermodynamics calculations).

TABLE 3 | Calculated compared with measured methane pressure (leaving the microreactor) and $\mathrm{CO}_{2}$ conversion for the monometallic Ni/SBA-15 catalyst samples at $550,600,650$, and $700^{\circ} \mathrm{C}$, respectively.

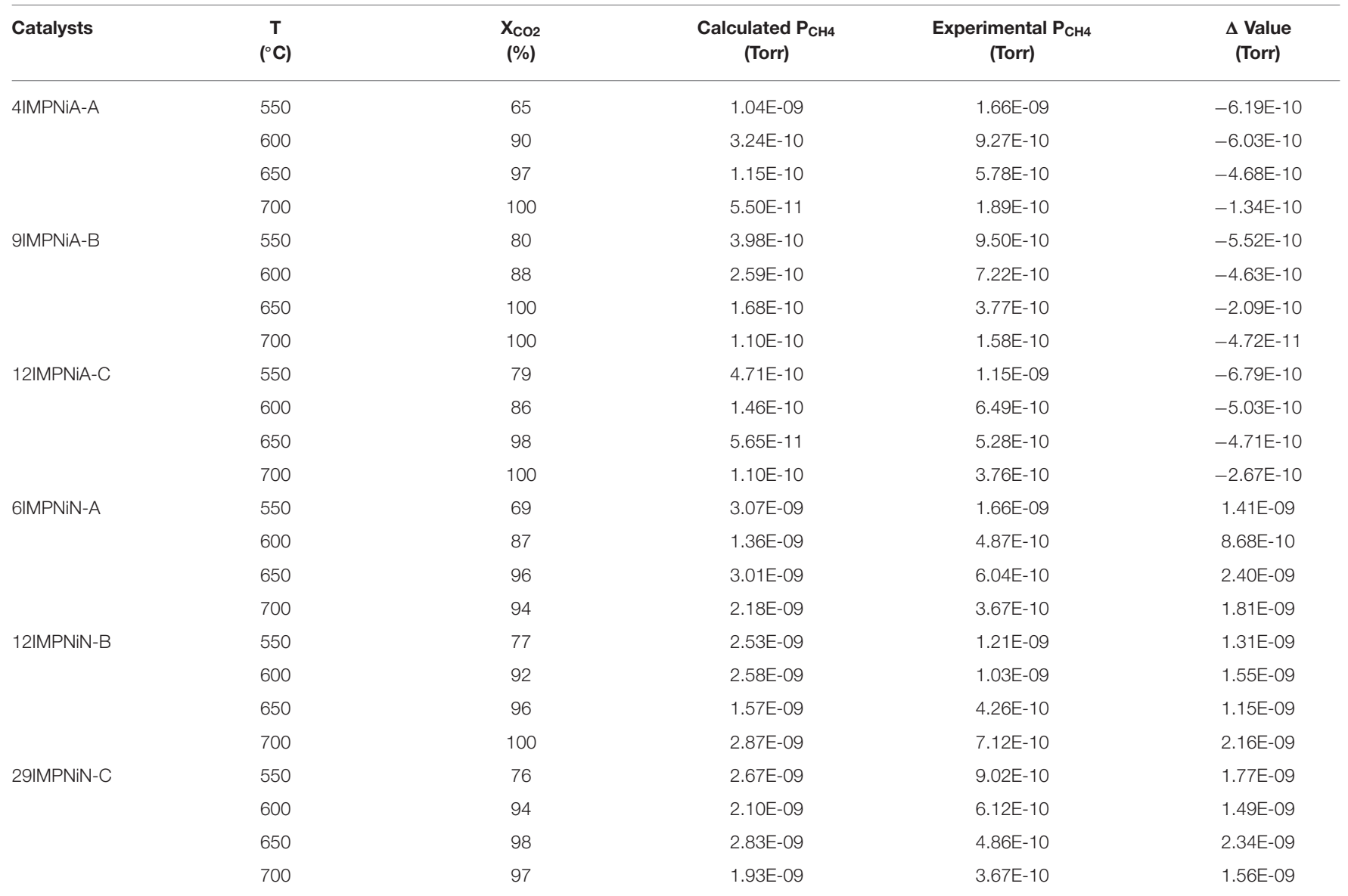


Therefore, let us consider that if coke is formed, it is formed through reaction 3 only. But, if there is no coke formed over the catalysts, only reaction 1 and 2 should have occurred. As reaction 1 is more endothermic than reaction 2, one can assume that mainly only reaction 1 occurred. If this is the case, the value for $\Delta$, as defined above, should be, if not zero, a very small negative one. Following the same reasoning, if coke is formed, $\Delta$ should have a positive value.

Although the method was developed using the mass spectrometry results, it can be applied to other techniques which allow the measurement of the exit gas composition (such as gas chromatography, Raman spectroscopy, and Fourier transform infrared spectrometry).

\section{RESULTS}

\section{Monometallic Ni/SBA-15 Samples}

Table 3 presents the calculated and experimentally-measured methane pressure values at the exit of the microreactor, along with their difference, and the carbon dioxide conversion at four temperatures, i.e., 550, 600, 650, and $700^{\circ} \mathrm{C}$, respectively, for the monometallic Ni/SBA-15 samples. The difference between the two pressure values is negative for the samples for which the nickel acetate was used as precursor, while for the samples prepared by using nickel nitrate as nickel precursor during impregnation the difference is positive.

If the proposed procedure is correct, then there should not be any coke formation during the DRM reaction over the catalysts prepared with nickel acetate, while the coke formation is expected over those catalysts prepared by using nickel nitrate as precursor.

Although nickel nitrate is the nickel precursor generally selected to prepare oxide-supported catalysts due to its low
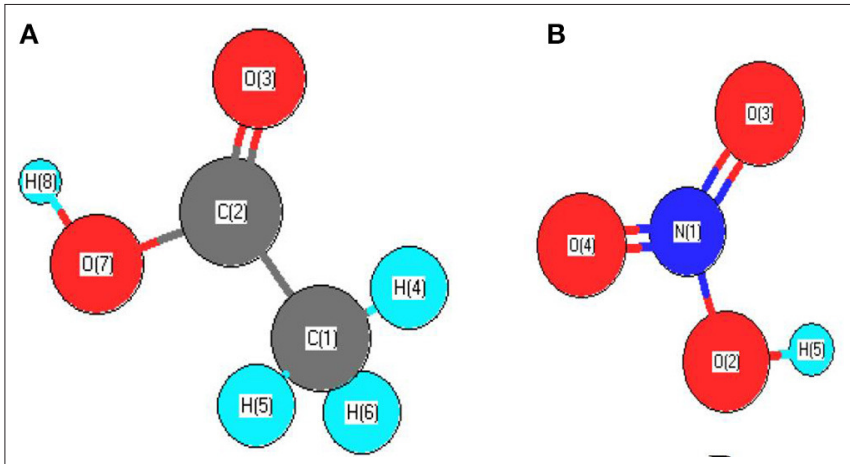

FIGURE 2 | (A) Geometry structure of acetic acid; (B) Geometry structure of nitric acid (Ahmed, 2013).
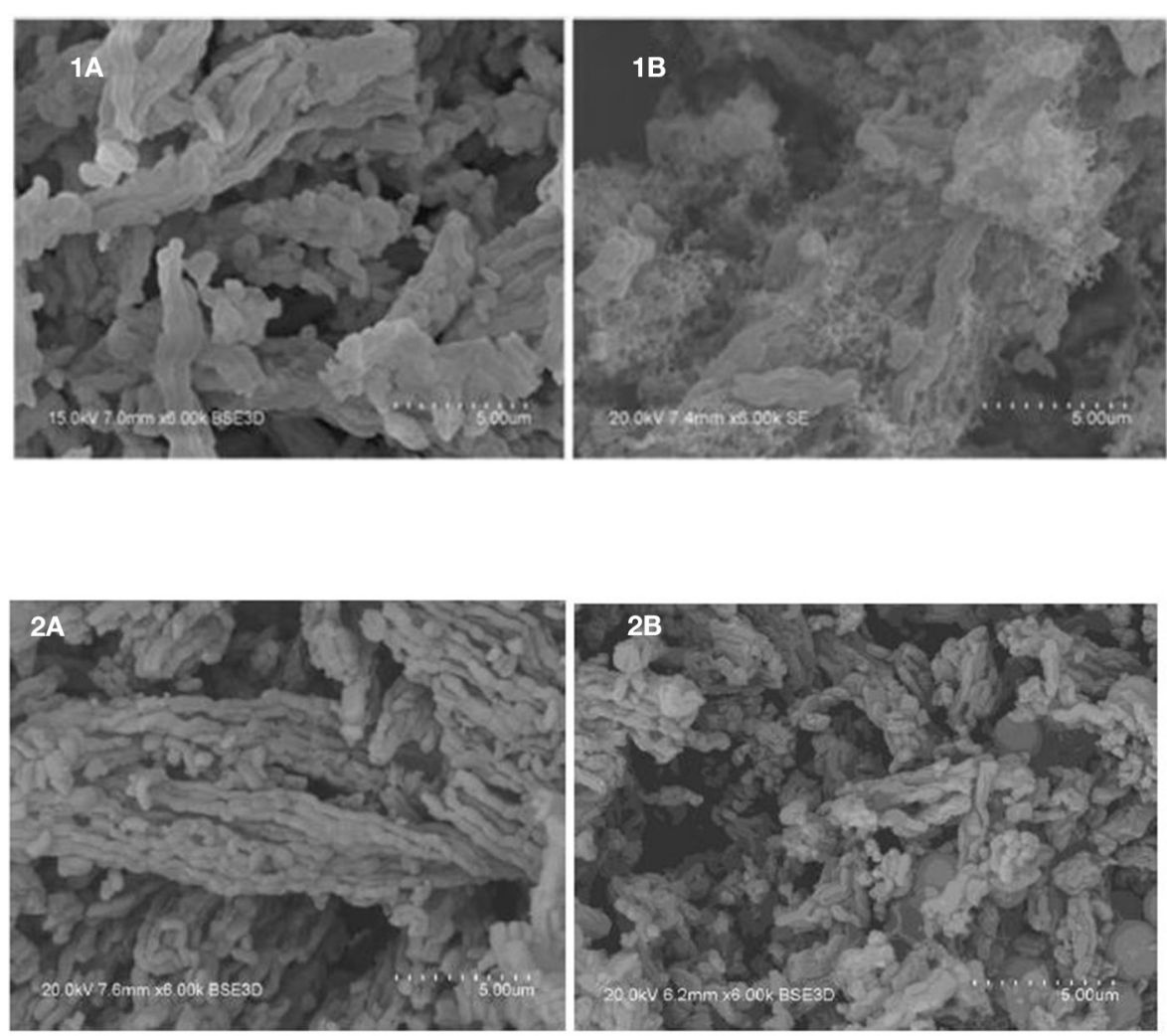

FIGURE 1 | SEM images of (1A) 9IMPNiA-B and (1B) $12 \mathrm{IMPNiN-B}$ spent catalysts $\left(550^{\circ} \mathrm{C}\right)$. SEM images of (2A) $9 \mathrm{MMPNiA}-\mathrm{B}$ and (2B) $12 \mathrm{IMPNiN-B}$ fresh catalysts. 
cost, high solubility in water, and decomposition at moderate temperatures, there are disadvantages in using it as a precursor. Its decomposition produces non-stoichiometric nickel oxide $(\mathrm{NiOx})$ and it is known to melt and redistribute over the supporting material, leading to poorly dispersed metal particles after reduction and to their partial expulsion from the porous support system (Marceau et al., 2010). By using nickel acetate as a precursor, all these disadvantages are avoided.

The wide-angle XRD spectra showed that, for samples prepared with nitrate as precursor, the average $\mathrm{NiO}$ particle size was $10.0 \mathrm{~nm}$, while for those prepared with concentrate nickel acetate solution (sample 12IMPNiA-C), the average $\mathrm{NiO}$ particle size was $8.0 \mathrm{~nm}$. When diluted nickel acetate solution was used (sample 9IMPNiA-B), only very weak and broad reflection peaks are observed, indicating that exclusively uniformly dispersed, very small nickel oxide particles are formed (Ahmed, 2013).

In order to support these statements, SEM was performed on the fresh and spent catalysts samples discussed in Table 3. Figure 1 presents, comparatively, the SEM images obtained over the 9IMPNiA-B and 12IMPNiN-B spent catalyst samples Figures 1(1A,B) and fresh samples Figures 1(2A,B), respectively. Although both samples were prepared using the same SBA-15:Ni-salt:DI water weight ratio, increased Ni loading was observed when nitrate was the precursor. At the same time, it was noticed that the dispersion of the $\mathrm{NiO}$ species on the surface of the support, SBA-15, decreased by increasing the loading (Ahmed, 2013). The difference in dispersion can be explained by taking into account the size and geometry of acetic acid against the size and geometry of nitric acid (see Figure 2).

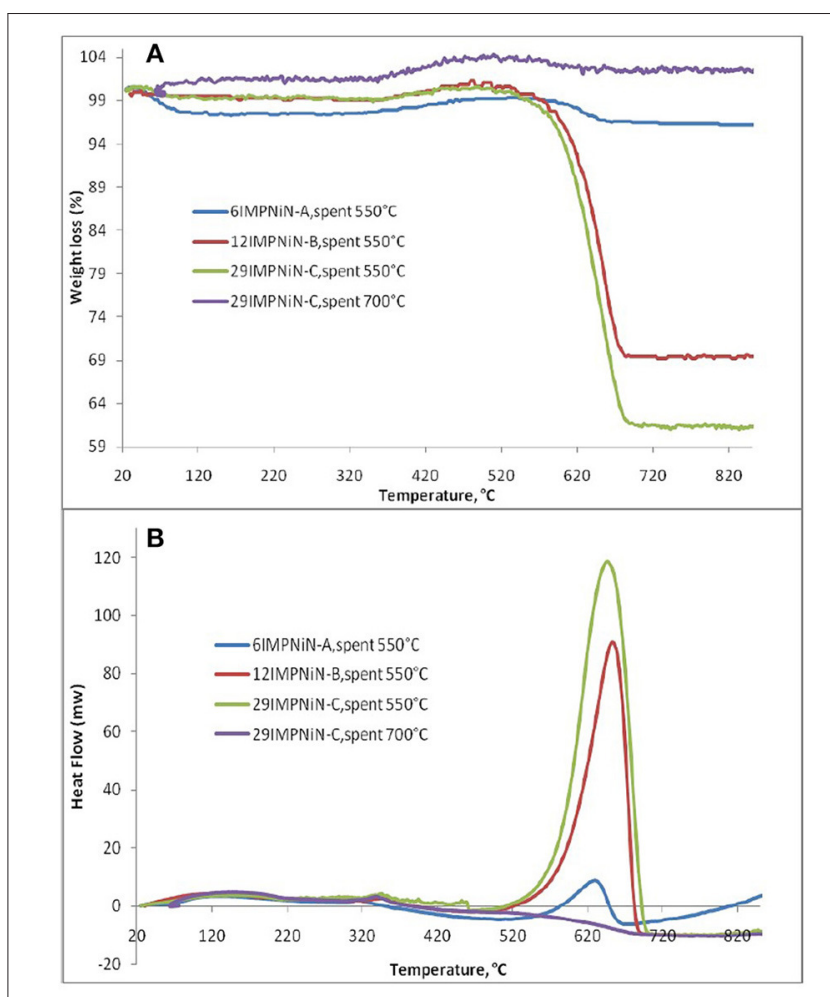

FIGURE 4 | TGA (A)/DSC (B) analysis of: 6IMPNiN-A spent at $550^{\circ} \mathrm{C}$, $12 \mathrm{IMPNiN}-\mathrm{B}$ spent at $550^{\circ} \mathrm{C}, 29 \mathrm{IMPNiN}-\mathrm{C}$ spent at $550^{\circ} \mathrm{C}$, and $29 \mathrm{IMPNiN}-\mathrm{C}$ spent at $700^{\circ} \mathrm{C}$ samples.

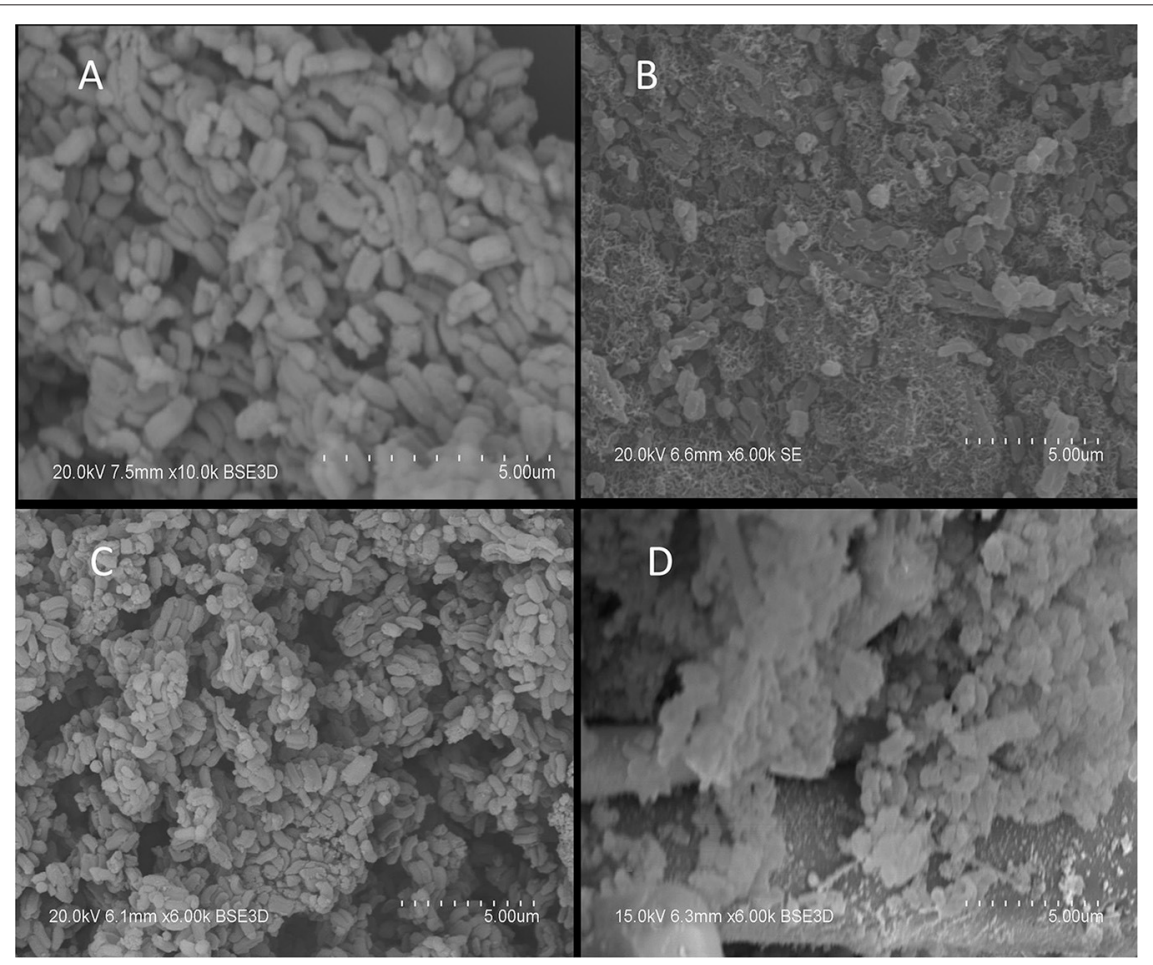

FIGURE 3 | SEM images of 6IMPNiN-A [(A) fresh and (B) spent, $550^{\circ} \mathrm{C}$ ] and $291 \mathrm{MPNiN}-\mathrm{C}$ [(C) fresh and (D) spent, $\left.550^{\circ} \mathrm{C}\right]$ catalysts. 
As the first one is a bigger molecule, it will favor the dispersion of $\mathrm{Ni}$ species on the support; as the second one is a smaller molecule, it will favor more Ni loading on the SBA-15 supports with the same BET surface area. Moreover, the nature of the precursor influenced the structure of the reduced species as well. Wide-angle XRD taken after reduction showed the nickel metallic species was well-dispersed for the samples prepared with nickel acetate (their size was assumed to be $<3 \mathrm{~nm}$, as no reflection peaks were detected), while in the case of the samples prepared with nickel nitrate, nickel clusters were obtained after reduction. Their size increased from 8 to $20 \mathrm{~nm}$ as the Ni loading increased from 6 to $29 \mathrm{wt} \%$, respectively (Ahmed, 2013).

As predicted, there is no coke formation observed on the nickel acetate sample, while there is a considerable amount of coke formed during the dry reforming of methane reaction over the nickel nitrate catalyst sample.

Figure 3 presents, comparatively, the SEM images taken over two ex-nitrate samples, both fresh and spent 6IMPNiNA and 29IMPNiN-C samples, respectively. As predicted, there is coke formation over the spent catalyst samples. The amount of coke seems to increase with the increasing of the $\mathrm{Ni}$ loading; the particles are completely covered with carbon for the 29 wt\% Ni loading.

Furthermore, to determine the amount of carbon formed on the surface, the spent ex-nitrate catalysts were analyzed by using TGA/DSC. Figure 4A shows only one significant weight loss in the $550-695^{\circ} \mathrm{C}$ range, which is due to the combustion of coke deposited on the catalyst. Besides the weight loss, a slight weight

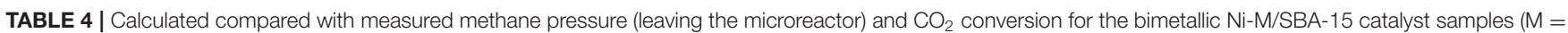
Co and La) (prepared by sequential impregnation and co-impregnation), at 550,600, 650, and $700^{\circ} \mathrm{C}$, respectively.

\begin{tabular}{|c|c|c|c|c|c|}
\hline Catalysts & $\begin{array}{c}\mathrm{T} \\
\left({ }^{\circ} \mathrm{C}\right)\end{array}$ & $\begin{array}{c}X_{\text {co2 }} \\
(\%)\end{array}$ & $\begin{array}{c}\text { Theoretical, } \mathrm{P}_{\mathrm{CH} 4} \\
\text { (Torr) }\end{array}$ & $\begin{array}{c}\text { Practical, } \mathrm{P}_{\mathrm{CH} 4} \\
\text { (Torr) }\end{array}$ & $\begin{array}{c}\Delta \text {-value } \\
\text { (Torr) }\end{array}$ \\
\hline \multirow[t]{4}{*}{ 9IMPNi2CoA-A } & 550 & 74 & $5.82 \mathrm{E}-10$ & 1.09E-09 & $-5.11 E-10$ \\
\hline & 600 & 89 & $4.68 \mathrm{E}-10$ & 8.92E-10 & $-4.24 \mathrm{E}-10$ \\
\hline & 650 & 95 & $3.51 \mathrm{E}-10$ & $3.72 \mathrm{E}-10$ & $-2.07 E-11$ \\
\hline & 700 & 100 & $5.40 \mathrm{E}-11$ & $2.63 E-10$ & $-2.09 E-10$ \\
\hline \multirow[t]{4}{*}{ 15IMPNi4CoA-B } & 550 & 70 & 8.06E-10 & 1.10E-09 & $-2.91 E-10$ \\
\hline & 600 & 90 & $2.84 \mathrm{E}-10$ & $8.49 \mathrm{E}-10$ & $-5.65 E-10$ \\
\hline & 650 & 95 & $5.83 \mathrm{E}-11$ & $3.63 \mathrm{E}-10$ & $-3.04 \mathrm{E}-10$ \\
\hline & 700 & 100 & $1.64 \mathrm{E}-10$ & $3.48 \mathrm{E}-10$ & $-1.84 \mathrm{E}-10$ \\
\hline \multirow[t]{4}{*}{ 16IMPNi8CoA-C } & 550 & 85 & $3.68 \mathrm{E}-10$ & 1.18E-09 & $-8.13 E+10$ \\
\hline & 600 & 94 & $3.44 \mathrm{E}-10$ & 8.30E-10 & $-4.84 \mathrm{E}-10$ \\
\hline & 650 & 100 & $2.84 \mathrm{E}-10$ & 4.66E-09 & $-1.83 \mathrm{E}-10$ \\
\hline & 700 & 100 & $1.10 \mathrm{E}-10$ & $3.63 \mathrm{E}-10$ & $-2.53 \mathrm{E}-10$ \\
\hline \multirow[t]{4}{*}{ 10IMPNi6LaN-A } & 550 & 41 & 3.46E-09 & 2.36E-10 & 3.23E-09 \\
\hline & 600 & 89 & $9.50 \mathrm{E}-10$ & 8.10E-10 & $1.41 \mathrm{E}-10$ \\
\hline & 650 & 96 & $3.44 \mathrm{E}-10$ & $2.64 \mathrm{E}-10$ & 8.07E-11 \\
\hline & 700 & 100 & $5.66 \mathrm{E}-10$ & 4.34E-10 & $1.32 \mathrm{E}-10$ \\
\hline \multirow[t]{4}{*}{ 13IMPNi18LaN-B } & 550 & 80 & 2.64E-09 & 1.13E-09 & $1.51 \mathrm{E}-09$ \\
\hline & 600 & 85 & 2.74E-09 & 1.10E-09 & 1.65E-09 \\
\hline & 650 & 100 & $9.88 \mathrm{E}-10$ & $2.28 \mathrm{E}-10$ & $7.59 \mathrm{E}-10$ \\
\hline & 700 & 100 & $1.35 E-10$ & $3.70 \mathrm{E}-10$ & $9.80 \mathrm{E}-10$ \\
\hline \multirow[t]{4}{*}{ 16IMPNi11LaN-C } & 550 & 75 & 4.92E-09 & 1.14E-09 & 3.78E-09 \\
\hline & 600 & 91 & 2.24E-09 & $6.35 \mathrm{E}-10$ & 1.60E-09 \\
\hline & 650 & 98 & $1.12 \mathrm{E}-09$ & $2.87 \mathrm{E}-10$ & 8.36E-10 \\
\hline & 700 & 96 & 7.93E-10 & $3.47 \mathrm{E}-10$ & $4.46 \mathrm{E}-10$ \\
\hline \multirow[t]{4}{*}{ 12COIMPNi11CoN-C } & 550 & 77 & $5.82 \mathrm{E}-10$ & $4.22 \mathrm{E}-10$ & $1.59 \mathrm{E}-10$ \\
\hline & 600 & 83 & $6.43 E-10$ & $4.29 \mathrm{E}-10$ & $2.13 E-10$ \\
\hline & 650 & 96 & $4.03 E-10$ & $2.17 \mathrm{E}-10$ & $1.86 \mathrm{E}-10$ \\
\hline & 700 & 100 & $6.55 \mathrm{E}-10$ & $1.79 \mathrm{E}-10$ & $4.76 \mathrm{E}-10$ \\
\hline \multirow[t]{4}{*}{ 4COIMPNi12LaN-B } & 550 & 64 & 1.30E-09 & $8.16 \mathrm{E}-10$ & $4.98 \mathrm{E}-10$ \\
\hline & 600 & 81 & 1.20E-09 & $5.76 \mathrm{E}-10$ & 6.36E-10 \\
\hline & 650 & 92 & $7.08 \mathrm{E}-10$ & $2.10 \mathrm{E}-10$ & $4.97 \mathrm{E}-10$ \\
\hline & 700 & 100 & $4.90 \mathrm{E}-10$ & $1.50 \mathrm{E}-10$ & $3.43 E-10$ \\
\hline
\end{tabular}


gain caused by the oxidation of metallic $\mathrm{Ni}$ particles was also observed. The higher the Ni loading, the higher the amount of coke deposited for the spent samples in the DRM reaction at $550^{\circ} \mathrm{C}$. There was a $2.8 \%$ weight loss for the $6 \mathrm{IMPNiN}-\mathrm{A}$ spent sample. For the 12IMPNiN-B spent sample, the weight loss was $30.5 \%$, while for the 29IMPNiN-C spent catalyst the weight loss was $37.9 \%$. But almost no weight loss was observed for the used samples in the reaction run at $700^{\circ} \mathrm{C}$. This is an expected result as at higher reaction temperatures the carbon gasification side reaction can occur as well. The DSC curves (see Figure 4B) of the samples show two exothermic peaks: (i) a small one at lower temperatures, which can be assigned to the oxidation of metallic nickel to $\mathrm{Ni}^{2+}$; and (ii) a strong one at higher temperatures which is due to the gasification of carbon. As the DSC curves present only one strong exothermic peak, one can conclude that only one kind of carbonaceous species was deposited on the surface of these catalysts, most likely graphite-like carbon (Guczi et al., 2010; result supported by the XRD measurements and by Ahmed, 2013).

In addition, to explain why almost no coke formation was observed at $700^{\circ} \mathrm{C}$, we assumed that at a higher reaction temperature the carbon gasification side reaction can occur as well. Ahmed (2013) performed the Temperature Programmed Oxidation reaction over the spent catalysts.

As the TPO results have shown, a broad but low intensity $\mathrm{CO}_{2}$ peak, centered around $650^{\circ} \mathrm{C}$, was observed for the 29IMPNiN$\mathrm{C}$ sample. This means that some strongly bonded carbon species were deposited during the DRM reaction. As for the XRD results, they were graphite species (Guczi et al., 2010). (Even lower amounts of carbon were formed on the other two Ni ex-nitrate samples, but they were not detectable by TPO). No $\mathrm{CO}_{2}$ peaks were observed for the $\mathrm{Ni}$ ex-acetate catalysts. What was more, in
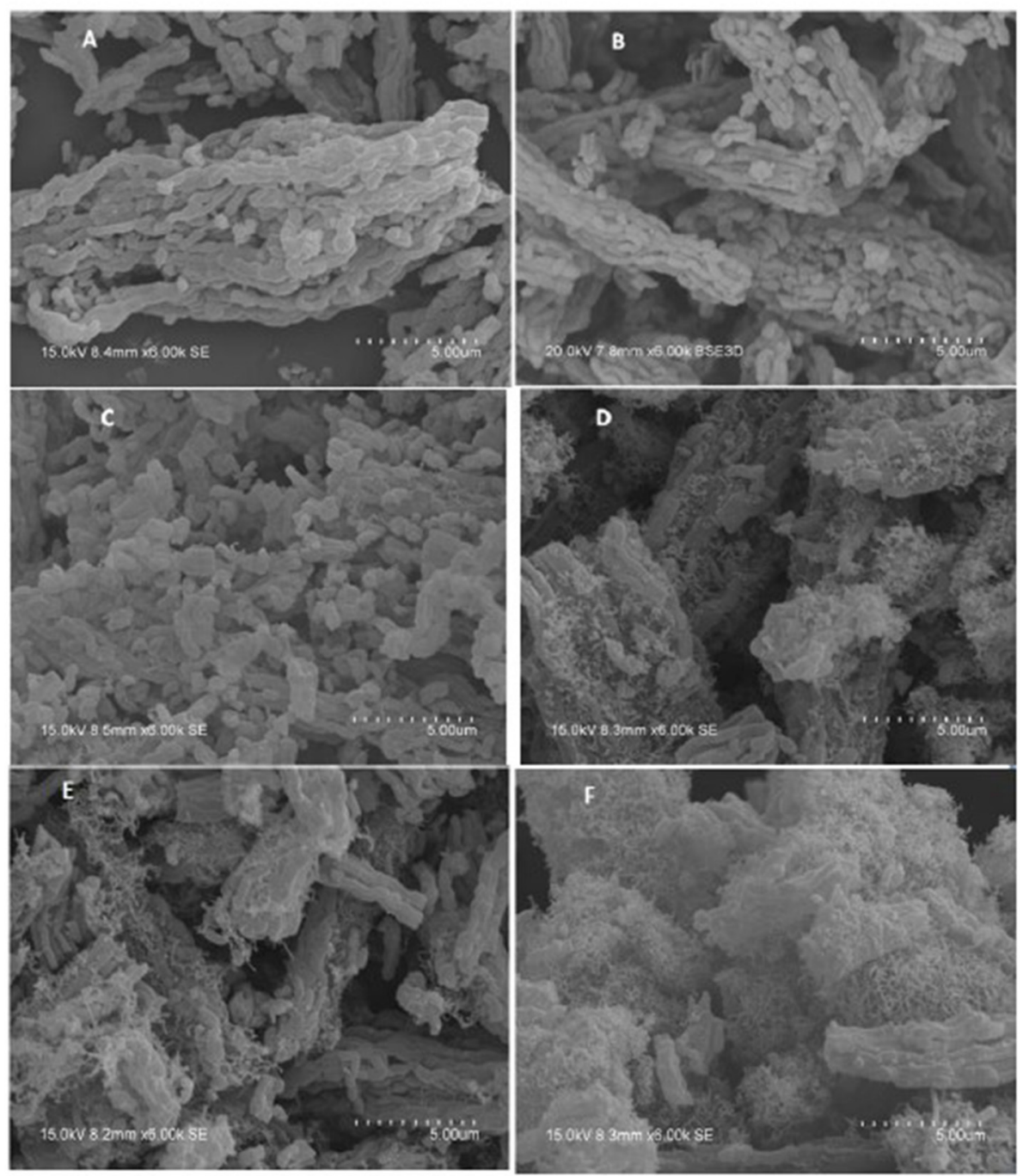

FIGURE 5 | SEM images of (A) 9IMPNi2CoA-A, (B) 15IMPNi4CoA-B, (C) 16IMPNi8CoA-C, (D) 10IMPNi6LaN-A, (E) 13IMPNi18LaN-B, and (F) 16IMPNi11LaN-C spent samples at $550^{\circ} \mathrm{C}$. 
this TPO experiment, there was no signal for water, which was in line with previous work (Liu et al., 2009b).

One can conclude that the size of the Ni particles, which in turn depends on the nature of the nickel precursor and nickel loading, is responsible for their resistance toward carbon formation: the smaller the size, the higher the resistance.

Our results confirmed the importance of minimizing the $\mathrm{Ni}$ particle size in minimizing the coke deposition on Ni-based catalysts, as carbon deposition on an Ni surface is known to necessitate $\mathrm{Ni}$ ensembles, and large $\mathrm{Ni}$ particles cause more severe coke deposition (Han et al., 2017 and References herewith). Theoretical studies revealed that if the $\mathrm{Ni}$ facets or step edges were small enough, which was the case for nickel particles $<10 \mathrm{~nm}$, nucleation of graphene could not proceed and graphite formation was further suppressed (Bengaard et al., 2002). Olea et al. (2014), proposed an optimized method to deposit welldispersed Ni particles into SBA-15 mesoporous silica, to avoid coke deposition and sintering as well. Also, our results are in line with published results on nickel-grafted SBA-15 by Liu et al. (2009b), which confirmed that the highest catalytic activity and long-term stability were obtained over a 5 wt.\% Ni/SBA-15 catalyst, with $\mathrm{Ni}$ species well-dispersed into the high surface area of SBA-15. This superior catalytic behavior was closely related with the strong resistance toward carbon formation and active metal sintering.

There is another important factor which contributes to the stability of the Ni-based catalysts. As the dry reforming reaction typically occurs at very high temperatures, the initially small $\mathrm{Ni}$ particles become sintered and the size of the $\mathrm{Ni}$ domains eventually becomes large with heavy coke deposition. Strong metal-support interactions are often used to maintain the small size of the $\mathrm{Ni}$ particles at high reaction temperatures. A way to quantify the metal-support interactions is to study the kinetics of the $\mathrm{H}_{2}$-reduction of the calcined samples. Ahmed (2013), found that for the catalysts prepared using nickel nitrate as precursor that the activation energy for the reduction process decreased as the Ni-loading increased, which means that the metal-support interaction is stronger at lower Ni loading. Accordingly, less carbon deposition should occur on the catalysts with lower $\mathrm{Ni}$ loading as compared with those with higher loading. Our TGA results support this statement.

\section{Bimetallic Ni-Metal/SBA-15 Samples (Me = Co and La)}

Table 4 presents the calculated and the experimentally measured methane pressure values at the exit of the microreactor along with their difference, and carbon dioxide conversion at four temperatures, i.e., 550, 600, 650, and $700^{\circ} \mathrm{C}$, respectively, for the bimetallic Ni-M/SBA-15 samples, prepared by both impregnation and co-impregnation. As stated above, if $\Delta$, the difference between the two pressure values, was zero or a very small negative value, then no carbon formation was expected over that catalyst. In contrast, when $\Delta$ was positive, some carbon formation is expected. Therefore, one can conclude that the Ni-Co catalysts prepared by sequential impregnation would not favor the carbon deposition during the DRM reaction, while the sequential impregnated $\mathrm{Ni}$-La samples and those obtained by co-impregnation would favor the coke formation. To confirm this statement, TGA/DSC and SEM measurements were performed over the spent catalysts in order to assess the carbon formation. Figures $\mathbf{5 A - F}$ shows the SEM morphologies of spent (at $550^{\circ} \mathrm{C}$ ) $\mathrm{Ni}-\mathrm{Co}$ and $\mathrm{Ni}-\mathrm{La}$ samples, obtained by sequential impregnation. There was no carbon deposition observed over all the Ni-Co catalysts, not even for the highest $\mathrm{Ni}$-Co loading sample (i.e., 16IMPNi8CoA-C). By contrast, some carbon deposited over the Ni-La catalysts was observed. The maximum amount of carbon deposited seems to be on the 16IMPNi11LaN-C sample. This observation was confirmed by the TGA measurements.

Figure 6A shows only one significant weight loss in the $550-695^{\circ} \mathrm{C}$ temperature range, which is due to the combustion of coke deposited on the catalyst. Besides the weight loss, a slight weight gain caused by the oxidation of metallic particles was also observed. There was a $7.8 \mathrm{wt} \%$ of weight loss for
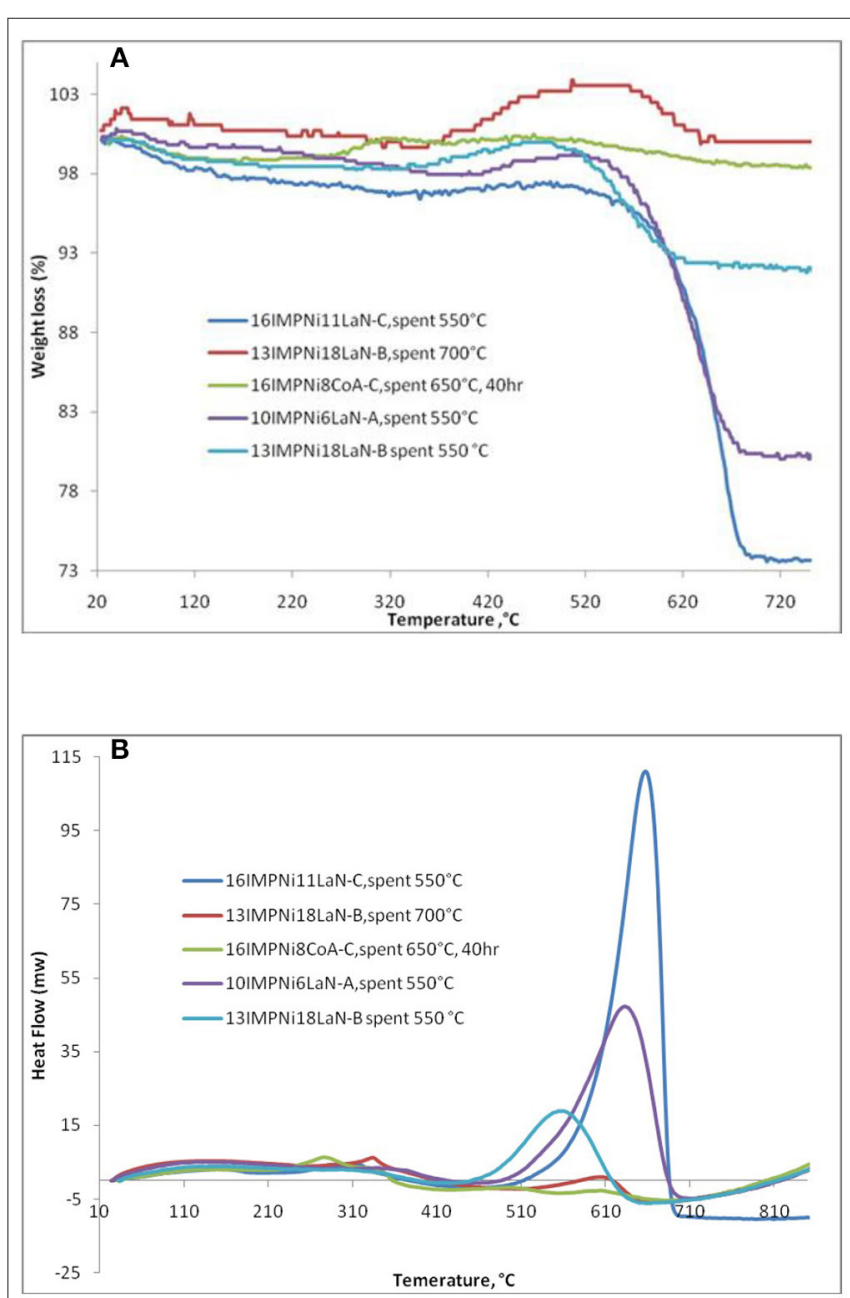

FIGURE 6 | TGA (A)/DSC (B) analysis of 10IMPNi6LaN-A, 13IMPNi18LaN-B, 16IMPNi11 LaN-C, and 16IMPNi8CoA-C spent samples. 

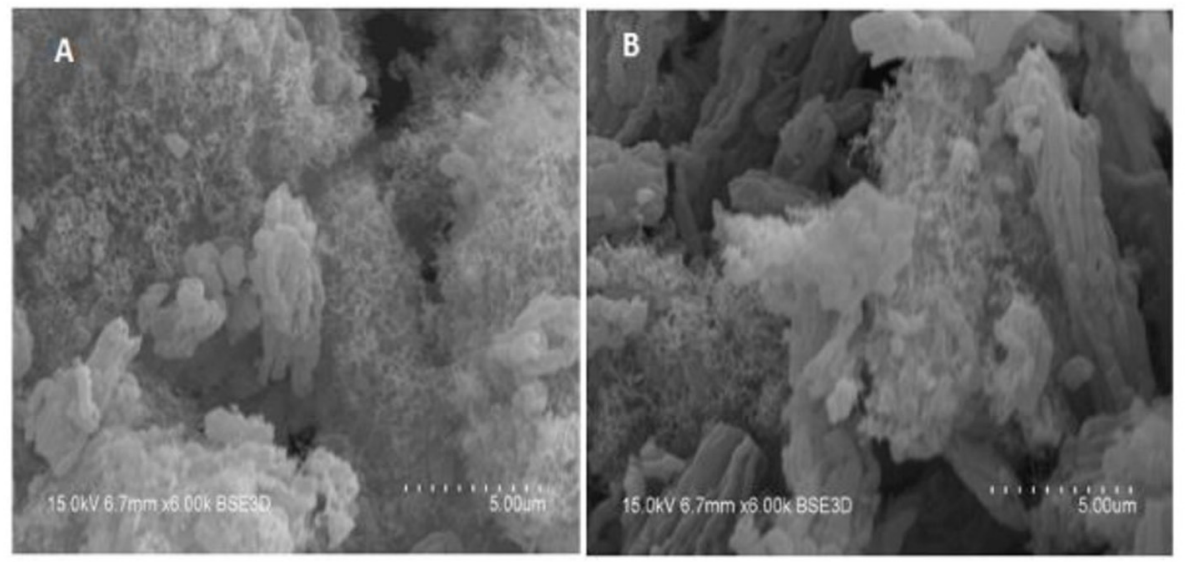

FIGURE 7 | SEM images of 12COIMPNi11CoN-C (A) and 4COIMPNi12LaN-B (B) samples after reaction at 550 ${ }^{\circ} \mathrm{C}$.
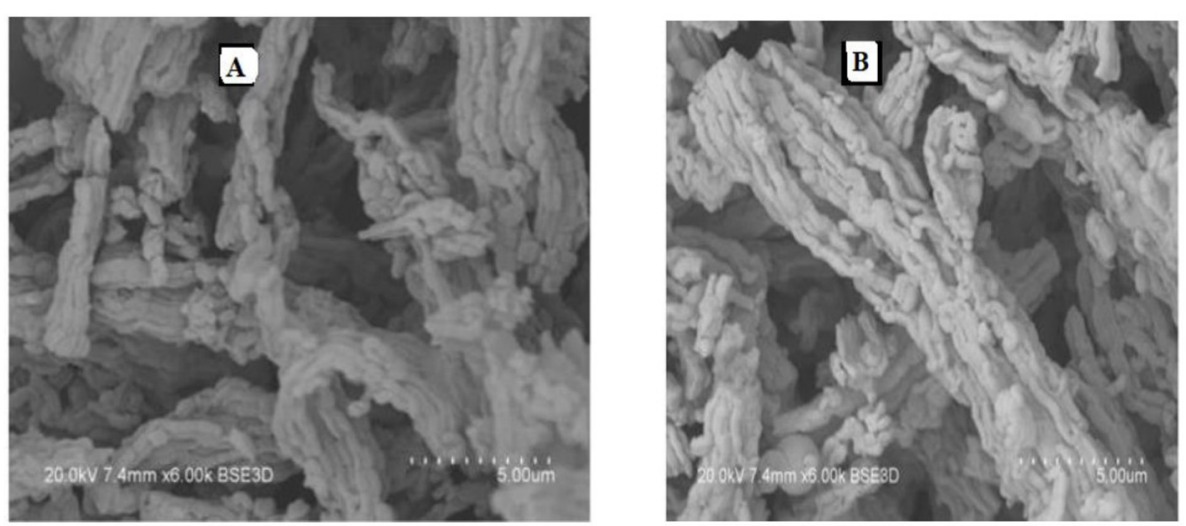

FIGURE 8 | SEM images of fresh samples 12COIMPNi11CoN-C (A) and 4COIMPNi12LaN-B (B).

the 13IMPNi18LaN-B spent sample. For the 10IMPNi6LaNA spent sample, the weight loss was $19.0 \mathrm{wt} \%$, while for the 16IMPNi11LaN-C spent catalyst the weight loss was $22.4 \mathrm{wt} \%$. But almost no weight loss was observed for the used samples in the reaction run at $700^{\circ} \mathrm{C}$. This is an expected result again as at higher reaction temperatures the carbon gasification side reaction can also occur. On the other hand, no weight loss was observed for all Ni-Co catalysts over $40 \mathrm{~h}$ time on stream (only 16IMPNi8CoA-C samples after reaction for $40 \mathrm{~h}$, shown here), indicating that the additional Co component in the catalyst had a great beneficial effect on the catalyst performance without carbon formation on the surface of the catalyst.

The DSC curves (see Figure 6B) of the samples show two exothermic peaks: (i) a small one at lower temperatures which can be assigned to oxidation of metallic nickel to $\mathrm{Ni}^{2+}$; and (ii) a strong one at higher temperatures, which is due to the gasification of carbon. As the DSC curves present only one strong exothermic peak, one can conclude that only one kind of carbon was deposited on the surface of these catalysts, most likely graphite-like carbon (Guczi et al., 2010; result supported by the XRD measurements as well, Ahmed, 2013).

There was some change in the intensities of the peaks for all samples, likely due to the different size of metal particles. The intensity of the DSC peaks gradually decreased with La content from the 10IMPNi6LaN-A to the 13IMPNi18LaN-B samples. This means that La actually played dual roles in preventing the carbon formation for the $\mathrm{CO}_{2}$ reforming of $\mathrm{CH}_{4}$. On the one hand, the basic $\mathrm{La}_{2} \mathrm{O}_{3}$ favored the chemisorption and dissociation of $\mathrm{CO}_{2}$ and subsequently accelerated the carbon elimination by $\mathrm{CO}_{2}+\mathrm{C} \rightarrow 2 \mathrm{CO}$. On the other hand, the $\mathrm{La}$ dispersed in the SBA-15 and Ni crystallites could prevent the $\mathrm{Ni}$ grains from excessive growth at high temperatures.

Figure 7 presents the SEM results over the 12COIMPNi11CoN-C and 4COIMPNi12LaN-B spent samples. If these results are compared with those obtained over the fresh catalysts as presented in Figure 8, one can say that there is carbon deposition over both co-impregnated spent samples, $\mathrm{Ni}-\mathrm{Co}$ and Ni-La. 

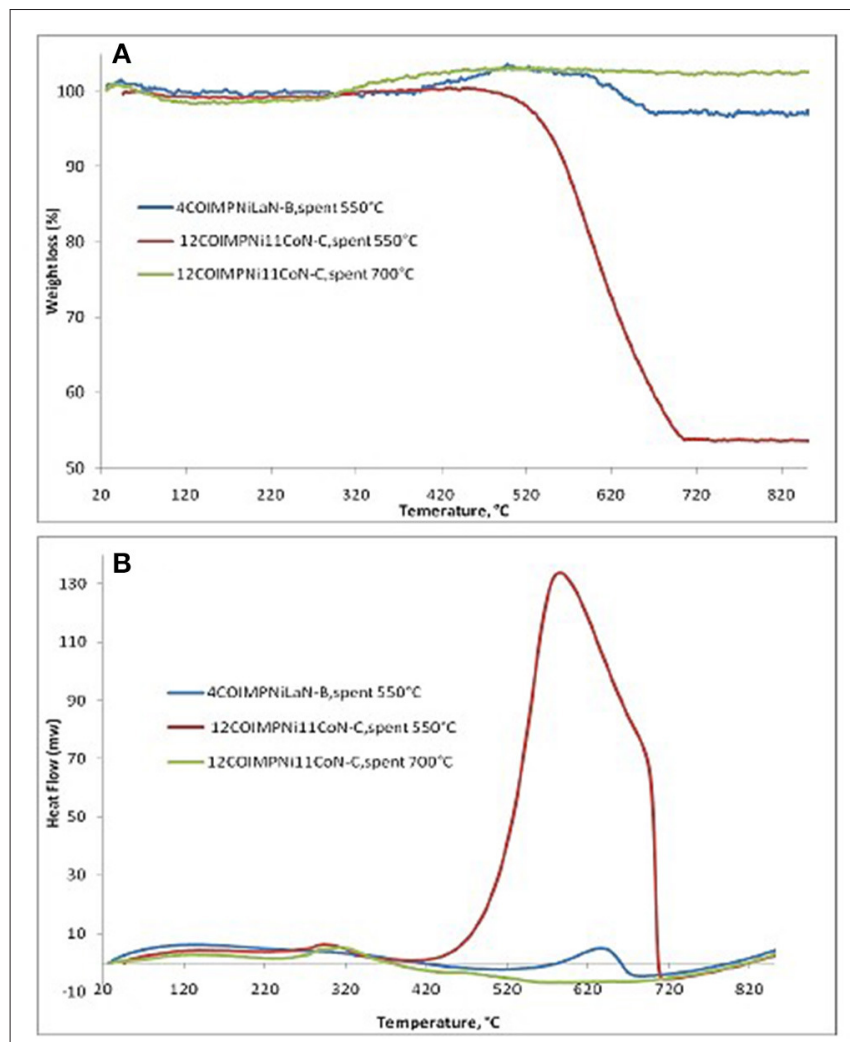

FIGURE 9 | TGA (A) and DSC (B) analysis of 12COIMPNi11CoN-C and 4COIMPNi12LaN-B spent samples.

Furthermore, to determine the amount of carbon formed on the surface of spent co-impregnated catalysts, TGA/DSC measurements were performed. Figure 9A shows only one significant weight loss in the $550-695^{\circ} \mathrm{C}$ range, which is due to the combustion of the coke deposited on the catalyst. Besides the weight loss, a slight weight gain caused by the oxidation of metallic Ni particles was also observed. The higher weight loss (45.9 wt\%), centered at a temperature range of $584-689^{\circ} \mathrm{C}$ was observed for the $12 \mathrm{COIMPNi11CoN-C} \mathrm{sample}$ after the reaction at $550^{\circ} \mathrm{C}$, while this weight loss is about $5.8 \mathrm{wt} \%$ for the 4COIMPNi12LaN-C sample. But almost no weight loss was observed for the used samples in the reaction run at $700^{\circ} \mathrm{C}$.

The DSC curves (see Figure 9B) of the samples show two exothermic peaks: (i) a small one at lower temperatures which can be assigned to oxidation of metallic nickel to $\mathrm{Ni}^{2+}$; and (ii) a strong one at higher temperatures, which is due to the gasification of carbon. As the DSC curves present only one strong exothermic peak, one can conclude again that only one kind of carbon species was deposited on the surface of these catalysts, most likely graphite-like carbon.

Bimetallic Ni-Co/SBA-15 catalysts were considered as it has been proven that the addition of Co increases the basicity of catalysts and enhances the $\mathrm{CO}_{2}$ adsorption, which effectively reduces the carbon deposition rate (Huang et al., 2015). As for the bimetallic Ni-La/SBA-15 catalysts, it has been found that the addition of a suitable amount of $\mathrm{La}$ as promoter increased the dispersion of $\mathrm{NiO}$ along with the interaction between $\mathrm{NiO}$ and silica support (Zhu et al., 2011).

\section{CONCLUSIONS}

In summary, an original method based on the analysis of the gas composition at the exit of the reactor, to predict, and monitor the carbon deposition during the dry reforming of the methane process over Ni-based catalysts, was proposed and tested on monometallic Ni/SBA-15 and bimetallic Ni-Co/SBA-15 and NiLa/SBA-15 catalysts. As the prediction results were accurate when compared with the experimental ones, the method can be successfully used not only to predict whether the formation of coke is likely to occur but also to monitor the DRM process at different scales. The current research confirmed that the size of the Ni particles, which in turn depends on the nature of the nickel precursor and loading and on the preparation methods, is responsible for the coke formation: the smaller the size, the less probable the carbon deposition.

\section{DATA AVAILABILITY STATEMENT}

The raw data supporting the conclusions of this article will be made available by the authors, without undue reservation, to any qualified researcher.

\section{AUTHOR CONTRIBUTIONS}

RA performed most of the experimental work. TS contributed to the physical characterization of the samples. MO proposed the prediction method, analyzed the data, and wrote the paper. All authors contributed to the article and approved the submitted version.

\section{SUPPLEMENTARY MATERIAL}

The Supplementary Material for this article can be found online at: https://www.frontiersin.org/articles/10.3389/fceng. 2020.00009/full\#supplementary-material

\section{REFERENCES}

Ahmed, R. (2013). High-efficiency catalysts for dry reforming of methane. (PhD thesis). Teesside University, Middlesbrough, United Kingdom.

Akri, M., Zhao, S., Li, X., Zang, K., Lee, A. F., Isaacs, M. A., et al. (2019). Atomically dispersed nickel as coke-resistant active sites for methane dry reforming. Nat. Commun. 10:5181. doi: 10.1038/s41467-019-1 2843-w 
Al-Fatish, A. S. A., Ibrahim, A. A., Fakeeha, A. H., Soliman, M. A., Siddiqui, M. R. H., and Abasaeed, A. E. (2009). Coke formation during $\mathrm{CO}_{2}$ reforming of $\mathrm{CH}_{4}$ over alumina-supported nickel catalysts. Appl. Catal. A 364, 150-155. doi: 10.1016/j.apcata.2009.05.043

Arbag, H., Yasyerli, S., Yasyerli, N., Dogu, G., and Dogu, T. (2016). Enhancement of catalytic performance of Ni based mesoporous alumina by Co incorporation in conversion of biogas to synthesis gas. Appl. Catal. B Environ. 198, 254-265. doi: 10.1016/j.apcatb.2016.05.064

Bengaard, H. S., Nørskov, J. K., Sehested, J., Clausen, B. S., Nielsen, L. P., Molenbroek, A. M., et al. (2002). Steam reforming and graphite formation on Ni catalysts. J. Catal. 209, 365-384. doi: 10.1006/jcat.2002.3579

Benrabaa, R., Löfberg, A., Caballero, J. G., Bordes-Richard, E., Rubbens, A., Vannier, R.-N., et al. (2015). Sol-gel synthesis and characterization of silica supported nickel ferrite catalysts for dry reforming of methane. Catal. Comm. 58, 127-131. doi: 10.1016/j.catcom.2014.09.019

Bradford, M. C. J., and Vannice, M. A. (1999). The role of metalsupport interactions in $\mathrm{CO}_{2}$ reforming of $\mathrm{CH}_{4}$. Catal. Today 50, 87-96. doi: 10.1016/S0920-5861(98)00465-9

Edwards, J. H., and Maitra, A. M. (1995). The chemistry of methane reforming with carbon dioxide and its current and potential applications. Fuel Proces. Technol. 42, 269-289. doi: 10.1016/0378-3820(94)00105-3

Erdogan, B., Arbag, H., and Yasyerli, N. (2018). SBA-15 supported mesoporous Ni and Co catalysts with high coke resistance for dry reforming of methane. Int. J. Hydrogen Energy 43, 1396-1405. doi: 10.1016/j.ijhydene.2017.11.127

Guczi, L., Stefler, G., Geszti, O., Sajó, I., Pászti, Z., Tompos, A., et al. (2010). Methane dry reforming with $\mathrm{CO}_{2}$ : A study on surface carbon species. Appl. Catal. A General 375, 236-246. doi: 10.1016/j.apcata.2009. 12.040

Han, J. W., Park, J. S., Choi, M. S., and Lee, H. J. (2017). Uncoupling the size and support effects of Ni catalysts for dry reforming of methane. Appl. Catal. B Environ. 203, 625-632. doi: 10.1016/j.apcatb.2016.10.069

Huang, T., Huang, W., Huang, J., and Ji, P. (2015). High stability of Ni-Co/SBA-15 catalysts for $\mathrm{CH}_{4}$ reforming with $\mathrm{CO}_{2}$. Energy Sourcest A Recov. Util. Environ. Eff. 37, 510-517. doi: 10.1080/15567036.2011.585387

Hukkamäki, J., Suvanto, S., Suvanto, M., and Pakkanen, T. T. (2004). Influence of the pore structure of MCM-41and SBA-15 silica fibers on atomic layer chemical vapor deposition of cobalt carbonyl. Langmuir 20, 10288-10295. doi: 10.1021/la048610q

Lin, H.-P., Tang, C.-Y., and Lin, C.-Y. (2002). Detailed structural characterization of SBA-15 and MCM-41 mesoporous silicas on a high-resolution transmission electron microscope. J. Chin. Chem. Soc. 49, 981-988. doi: $10.1002 /$ jccs.200200140

Liu, D. P., Quek, X. Y., Cheo, W. N. E., Lau, R., Borgna, A., and Yang, Y. H. (2009a). MCM-41 supported nickel-based bimetallic catalysts with superior stability during carbon dioxide reforming of methane: effect of strong metal-support interaction. J. Catal. 266, 380-390. doi: 10.1016/j.jcat.2009. 07.004

Liu, D. P., Quek, X. Y., Wah, H. H. A., Zeng, G. M., Li, Y. D., and Yang, Y. H. (2009b). Carbon dioxide reforming of methane over nickel-grafted SBA-15 and MCM-41 catalyst. Catal. Today 148, 243-250. doi: 10.1016/j.cattod.2009.08.014
Marceau, E., Che, M., Cejka, J., and Zukal, A. (2010). Nickel (II) nitrate vs. acetate: influence of the precursor on the structure and reducibility of Ni/MCM-41 and Ni/Al-MCM-41 catalysts. ChemCatChem 2, 413-422. doi: $10.1002 /$ cctc. 200900289

Nikolla, E., Schwank, J., and Linic, S. (2007). Promotion of the long-term stability of reforming Ni catalysts by surface alloying. J. Catal. 250, 85-93. doi: $10.1016 /$ j.jcat.2007.04.020

Olea, M., Hodgson, S. N., and Ahmed, R. A. (2014). Metal catalysts supported on mesoporous material. WO 2014/125309 A3. Available online ta: https://patentscope2.wipo.int/search/en/detail.jsf;jsessionid\$= \$F64242B3B2D9A69E76E58AAB90F8EDD7?docId \$=\$WO2014125309\& tab\$=\$PCTDESCRIPTION

San José-Alonso, D., Illán-Gómez, M. J., and Román-Martínez, M. C. (2013). Low metal content $\mathrm{Co}$ and $\mathrm{Ni}$ alumina supported catalyst for $\mathrm{CO}_{2}$ reforming of methane. Int. J. Hydrogen Energy 38, 2230-2239. doi: 10.1016/j.ijhydene.2012.11.080

Steinhauer, B., Kasireddy, M. R., Radnik, J., and Martin, A. (2009). Development of Ni-Pd bimetallic catalysts for the utilization of carbon dioxide and methane by dry reforming. Appl. Catal. A General 366, 333-341. doi: 10.1016/j.apcata.2009.07.021

Tsai, H.-L., and Wang, C.-S. (2008). Thermodynamic equilibrium prediction for natural gas dry reforming in thermal plasma reformer. J. Chinese Inst. Eng. 31, 891-896. doi: 10.1080/02533839.2008.9671444

Verykios, X. E. (2003). Catalytic dry reforming of natural gas for the production of chemicals and hydrogen. Int. J. Hydrogen. Energ. 28, 1045-1063.

Xu, B. Q., Wei, J. M., Wang, H. Y., Sun, K. O., and Zhu, Q. M. (2001). Nano-Mg: novel preparation and applications support of $\mathrm{Ni}$ catalyst for $\mathrm{CO}_{2}$ reforming of methane. Catal. Today 68, 217-225. doi: 10.1016/S0920-5861(01)00303-0

Zhao, D., Feng, J., Huo, Q., Melosh, N., Fredrickson, G. H., Chmelka, B. F., et al. (1998a). Triblock copolymer syntheses of mesoporous silica with periodic 50 to 300 angstrom pores. Science 279, 548-552. doi: 10.1126/science.279.5350.548

Zhao, D., Huo, Q., Feng, J., Chmelka, B. F., and Stucky, G. D. (1998b). Nonionic triblock and star diblock copolymer and oligomeric surfactant synthesis of highly ordered, hydrothermally stable, mesoporous silica structures. J. Amer. Soc. 120, 6024-6036. doi: 10.1021/ja974025i

Zhu, J. Q., Peng, X. X., Yao, L., Shen, J., Tong, D. M., and Hu, C. W. (2011). The promoting effect of $\mathrm{La}, \mathrm{Mg}$, $\mathrm{Co}$ and $\mathrm{Zn}$ on the activity and stability of $\mathrm{Ni} / \mathrm{SiO}_{2}$ catalyst for CO reforming of methane. Int. J. Hydrogen Energy 36, 7094-7104. doi: 10.1016/j.ijhydene.2011.02.133

Conflict of Interest: The authors declare that the research was conducted in the absence of any commercial or financial relationships that could be construed as a potential conflict of interest.

Copyright (C) 2020 Ahmed, Sasaki and Olea. This is an open-access article distributed under the terms of the Creative Commons Attribution License (CC BY). The use, distribution or reproduction in other forums is permitted, provided the original author(s) and the copyright owner(s) are credited and that the original publication in this journal is cited, in accordance with accepted academic practice. No use, distribution or reproduction is permitted which does not comply with these terms. 